bureaus carrying on this work have led inevitably and properly to the questions submitted by Congress to the academy.

It is plainly desirable, therefore, that Congress should make immediate provision to guard against a continuance of the evils which arise from a lack of any definite plan for, and from the absence of any adequate correlation of, the scientific work of the government.

It appears to your committee that the best way to deal with the condition now confronting the government is to secure the appointment by Congress of a permanent board which shall meet at stated intervals in each year for the consideration of all questions of the inauguration, the continuance, and the interrelations of the various branches of governmental scientific work. We would suggest that such a board should consist of the heads of bureaus carrying on scientific work, of two delegates from each of the Houses of Congress, and of five to seven eminent men of science not connected with the government service.

By means of a few meetings per year, with authorization to secure the requisite information from the heads of departments and bureaus concerned, all of the complicated questions which now are at best only ill considered could be carefully determined with great advantage in point of economy and efficiency to the public service and with little or no additional expense thereto.

Such a board could take under consideration the prevailing lack of system and lack of correlation in the work in question and gradually remove these defects from existing bureaus and divisions of the public service. All questions of the assignment, of the conduct, of advisable consolidation, and of the economies of such work could be fully discussed and determined, in the best interests of the government by such a board. If the heads of bureaus and divisions were required to submit their projects and estimates for work to this board before transmission to the heads of departments and to Congress, all questions of the duplication of work, of the duplication of organizations, of the duplication of laboratories or equipments, and of the most economical assignment could be readily determined without interference in the details of management of the organizations concerned.

One of the most important functions of such a board should be that of the nomination or selection of men competent to take charge of new projects or to fill vacancies which may arise in the more important positions of the scientific work in question. It would thus be generally possible to prevent the assignment of an incompetent man to the charge of a highly technical or specialized branch of the public service. It would thus be possible also to secure men of the highest professional attainments and to prevent the calamity which has not infrequently occurred in the past of assigning important scientific work to unprofessional or incompetent men. It would thus be possible likewise to take advantage of the competition between different branches of the public service in the laudable desire of those branches to prove their efficiency by the accomplishment of the required work of the government in the best and most economical ways. Very respectfully submitted.

R. S. WOODWARD,

W. W. CAMPBELL, Chairman,

Edward L. Nichols, Arthur A. Noyes, Charles R. Van Hise

Washington, D. C., January 9, 1909

\section{RECENT WORK OF THE MOUNT WILSON SOLAR OBSERVATORY}

Monochromatic photographs of the sun have been made daily on Mount Wilson since October, 1905, with the Snow telescope and fivefoot spectroheliograph. The weather has been very favorable, permitting calcium, hydrogen and frequently iron images to be taken on 303 days in 1908, and on 113 consecutive days during the summer of 1907 . Prior to March, 1908, the hydrogen photographs were made with the light of the violet line $H \delta$. Since that time, with the aid of plates sensitized by Wallace's formula, excellent results have been obtained with the red hydrogen line $H a$. These record the phenomena of a region in the solar atmosphere higher than that previously 
explored, and reveal the existence of extensive vortices or cyclonic storms associated with sunspots. In general, the direction of rotation of the vortices is counter-clockwise in the northern hemisphere and clockwise in the southern, as in the case of terrestrial cyclones; but a few interesting exceptions, in which the direction of rotation was reversed, have been found. There can now be little doubt that what we see in the telescope as a sun-spot is the mass of vapor, cooled somewhat below the temperature of the photosphere, which lies at the center of an invisible vortex (Astrophysical Journal, Vol. XXVIII., pp. 100-16).

The discovery of these vortices suggested that the rapid revolution of electrically charged particles, emitted from carbon and other vapors at the high temperature of the sun, should produce a magnetic field in sun-spots. Tests made with the 30 -foot spectrograph of the tower telescope show all the characteristic phenomena of the Zeeman effect in the spot spectrum, and leave no doubt as to the existence of a magnetic field. The strength of the field has been found to range from about 2,800 to about 4,500 gausses in different spots. Vortices rotating in opposite directions show opposite polarities, the changes in the spectrum and in the polarization phenomena being precisely similar to those of a luminous source in a magnetic field when the current through the magnet is reversed. The results indicate that the magnetic field is produced by the revolution of negative corpuscles in the vortices (see Astrophysical Journal, Vol. XXVIII., pp. 315343). There is some evidence that the plane of polarization of light passing through the spot vapors is rotated through different angles in different parts of the umbra, but more observations of this phenomenon are needed. For this and other purposes a tower telescope 160 feet high, giving a solar image 16 inches in diameter, and a spectrograph 75 feet long, mounted in a well below the tower, should prove of the greatest service. These instruments are now being designed, and will soon be constructed in our Pasadena shop. ${ }^{1}$

1 This telescope, of small aperture (12 inches) and great focal length (150 feet), is designed exclusively for work on the sun, where a large
The above results are of some general interest, since they conclusively demonstrate for the first time the operation of electric phenomena in the sun. So far as the cause and nature of sun-spots are concerned, they seem to favor Emden's theory. An attempt is now being made to determine whether the sun as a whole is a magnet. The tests already completed indicate that extremely sensitive methods will be required to settle the question, and these will soon be applied.

The 60-inch reflecting telescope, which has been under construction in our instrument and optical shops during the last four years, is now in operation on Mount Wilson. Visual and photographic tests show this instrument to be of the highest optical and mechanical perfection, and reflect great credit upon Professor Ritchey, its designer, and those who have been associated with him in the extensive work of construction and erection. Photographs of nebulæ made by Professor Ritchey, and a series of photographs of the great nebula in Orion, made through a red screen by the writer, are of exquisite sharpness and perfection of detail. The star images are extremely small, and the wealth of faint stars shown leaves no doubt that in light-grasping power, as well as in optical resolution, the telescope will meet our highest expectations. One of the most gratifying results of these tests is the proof they afford of the excellence of the night conditions on Mount Wilson. For the last four consecutive nights (January 16, 17, 18, 19) the definition with the full aperture of 60 inches has been essentially perfect from a photographic standpoint. This is in the midst of the rainy season, when the atmosphere is far less steady than during the unbroken succession of clear days and nights of summer. A telescope of 100 inches aperture, or even larger, could certainly be used here to great advantage on nights such as we have already tested. Fortunately, Mr. John D. Hooker, of Los Angeles, has agreed to meet the expense image is required. The 60 -inch and 100 -inch reflecting telescopes, of great aperture and smaller focal length, are not suitable for solar observations, but will be used for the study of stars and nebulæ. 
of constructing a large mirror for this observatory. A disk of glass 100 inches in diameter and 13 inches thick, weighing $4 \frac{1}{2}$ tons, has recently been received at our Pasadena shop from the French Plate Glass Works at St. Gobain, France. Much time was consumed in filling our order, and it was hoped that the disk would prove suitable. This does not turn out to be the case, however, and another trial must be made. The observatory will experience no financial loss, as the disk had not been accepted. The loss in time will not be very serious, because of the great opportunities for research in unexplored fields afforded by the 60 -inch reflector. I have no doubt that the difficulties of making a homogeneous disk of these great dimensions will soon be successfully overcome, and that the Hooker telescope will be ready in time to extend the work of the 60 -inch reflector into territory which even this powerful instrument can not enter.

George E. Hale

\section{BROOKS MEMORIAL}

IN the Donovan room of McCoy Hall, Johns Hopkins University, the end of the old and beginning of the new year saw a memorable reunion of men who had worked in contact with Professor W. K. Brooks. Under the guidance of the chairman, Professor S. F. Clarke, many paid tribute to Brooks, the inspiring teacher, whose life at Williams and at Cambridge was vividly sketched by Professor Edward A. Birge, and whose career at the Johns Hopkins furnished the material for many pleasant recollections and expressions of esteem and of love by Professors E. B. Wilson, H. W. Conn, H. H. Donaldson, F. H. Herrick, M. M. Metcalf and others who were Brooks's pupils in later years.

Upon motion of Professor Harrison a committee was appointed to prepare a memorial volume in honor of their master.

Professor E. L. Mark and thirty-two other zoologists of Harvard, in attendance upon the scientific meetings in Baltimore, wrote to express their " sentiments of highest appreciation for the character of the work of William Keith Brooks."
It was hoped that the incidents of Professor Brooks's life at Penikese could be made vivid by one who was there with Brooks, but a telegram from President David Starr Jordan stated his regret that he could not be present to honor the memory of "the wisest of American naturalists." Others were also unable to come to Baltimore. The names of the sixty men actually present follows below:

Edward A. Birge, fellow student at Williams College, professor of zoology, University of Wisconsin.

Samuel Fessenden Clarke, Ph.D., 1874, professor of natural history, Williams College.

Edmund Beecher Wilson, Ph.D., 1881, professor of zoology, Columbia University.

Albert H. Tuttle, professor of biology, University of Virginia.

Basil Sollers, student, 1878-9, teacher in public schools, Baltimore.

William Henry Howell, Ph.D., 1884, professor of physiology, Johns Hopkins University.

Herbert William Conn, Ph.D., 1884, professor of biology, Wesleyan University.

Henry Herbert Donaldson, Ph.D., 1885, professor of neurology, University of Pennsylvania.

Frederick Schiller Lee, Ph.D., 1885, professor of physiology, Columbia University.

James Playfair McMurrich, Ph.D., 1885, professor of anatomy, University of Toronto.

Albro David Morrill, Beaufort Laboratory, 1885, professor of biology, Hamilton College.

George Theophilus Kemp, Ph.D., 1886, sometime professor of physiology, University of Illinois.

Louis J. Rettger, student, 1886-9, candidate for Ph.D., 1909, professor of physiology, Indiana State Normal School.

Charles L. Edwards, graduate student, 1886-9, professor of natural history, Trinity College.

F. L. Washburn, graduate student, 1886-7, state entomologist, Minnesota, and professor of entomology, University of Minnesota.

Edwin Linton, Beaufort, Laboratory, professor of zoology, Washington and Jefferson College.

Ethan Allen Andrews, Ph.D., 1887, professor of zoology, Johns Hopkins University.

Henry Gustav Beyer, Ph.D., 1887, medical inspector, United States Navy.

John Pendleton Campbell, Ph.D., 1888, professor of biology, University of Georgia.

Francis Hobart Herrick, Ph.D., 1888, professor of biology, Adelbert College. 